\title{
AMENDMENTS
}

\section{Author Correction: Titanium-carbide MXenes for work function and interface engineering in perovskite solar cells}

A. Agresti (D), A. Pazniak, S. Pescetelli (D), A. Di Vito, D. Rossi, A. Pecchia, M. Auf der Maur (D, A. Liedl, R. Larciprete (D), Denis V. Kuznetsov, D. Saranin (D) and A. Di Carlo (D)

Correction to: Nature Materials https://doi.org/10.1038/s41563-019-0478-1, published online 9 September 2019.

In the version of this Article originally published, the Fig. 1c $x$-axis label incorrectly read 'Binding energy (eV)'; it should have read 'Kinetic energy (eV)'. This has now been corrected.

Published online: 14 October 2019

https://doi.org/10.1038/s41563-019-0527-9

\section{Publisher Correction: Reply to: On the ferroelectricity of $\mathrm{CH}_{3} \mathrm{NH}_{3} \mathrm{Pbl}_{3}$ perovskites}

Yongtao Liu (D), Liam Collins, Roger Proksch, Songkil Kim (D), Brianna R. Watson, Benjamin Doughty (D), Tessa R. Calhoun (D), Mahshid Ahmadi, Anton V. levlev (D), Stephen Jesse, Scott T. Retterer, AlD. Belianinov (D), Kai Xiao, Jingsong Huang (D), Bobby G. Sumpter, Sergei V. Kalinin (D), Bin Hu and Olga S. Ovchinnikova

Correction to: Nature Materials https://doi.org/10.1038/s41563-019-0481-6, published online 16 September 2019.

In the version of this Matters Arising originally published, the DOI link of the article by A. D. Schulz et al. was incorrectly given as https://doi.org/10.1038/s41563-019-480-7; it should have been https://doi.org/10.1038/s41563-019-0480-7. The same DOI has also been corrected in ref. 1. 